See discussions, stats, and author profiles for this publication at: https://www.researchgate.net/publication/324215841

The High-Order and Conscious Emotion: Assessing the Foundations, Contributions, and Implications of LeDoux's Model of Conscious and Cognitive Emotion

Article in Activitas nervosa superior · March 2018

DOI: 10.1007/541470-018-0015-6

1 author:

2. Luiz Augusto Rosa

Universidade Federal de São Carlos

3 PUBLICATIONS 1 CITATION

SEE PROFILE

Some of the authors of this publication are also working on these related projects:

Project The neural underpinnings of high-order anxiety View project 


\title{
The High-Order and Conscious Emotion: Assessing the Foundations, Contributions, and Implications of LeDoux's Model of Conscious and Cognitive Emotion
}

\author{
Luiz Augusto Rosa ${ }^{1}$
}

Received: 30 January 2018 / Accepted: 2 March 2018

(C) Springer International Publishing AG, part of Springer Nature 2018

\begin{abstract}
In the literature on emotion, it is common to associate this phenomenon with unconscious and/or subcortical mechanisms directly linked to survival circuits, which is recurringly called "traditional view of emotion." However, LeDoux and Brown have recently proposed that emotion is a high-order and cortical process carried out by what he calls general networks of cognition (GNC), which consists mainly of prefrontal mechanisms. Here, I assess the new ideas brought by this model to the field. I assess on what this model is based, its explanatory power, and what it means for the interpretation and discussion of empirical data. I also discuss how LeDoux and Brown's model of conscious emotion explains and interprets some recurring topics in the literature on emotion, such as nonhuman emotional experience, prefrontal functioning, freezing behavior, emotion regulation, and pleasure mechanisms. Above all, my goal is to provide theoretical tools for empirical and theoretical discussions on this recent issue.
\end{abstract}

Keywords Emotion $\cdot$ Cognition $\cdot$ Consciousness $\cdot$ High-order representation $\cdot$ Theoretical model $\cdot$ HOTEC

Until recently, it was common to classify numerous unconscious processes that are carried out prior to the conscious emotional experience as emotion or affect. Some authors, as Damasio (1999, 2010), even make a distinction between "unconscious" and "conscious" emotional processes, calling them emotion and feeling, respectively. However, LeDoux $(2012,2015)$ has recently proposed that emotion is, instead, always a cognitive and conscious process, not existing, therefore, any conceptual difference between "emotion" and "feeling." In addition, LeDoux and colleagues have proposed that the link between emotion and unconscious and/or subcortical processes carried out prior to the conscious emotional experience is only indirect, since these authors attribute (conscious) emotional states only to frontal functioning (LeDoux and Brown 2017).

Thus, since LeDoux and Brown's model of emotion has brought important and provocative ideas to the field, and there is the possibility of this model becoming a reliable model of

Luiz Augusto Rosa

augustorosa@marilia.unesp.br

1 School of Philosophy and Sciences, São Paulo State University (UNESP), Av. Hygino Muzzi Filho, 737, São Paulo, Marília, Brazil emotion, an evaluative and integrative review on this topic has become highly necessary. Therefore, my goal here is to analyze on what theoretical background this model is based, its explanatory power, and what it means to the analysis and discussion of neuroscientific and psychological data on emotions. My central goal is to show both how the model of consciousness embraced by the author (HOROR theory) influences his model of emotion and how this model changes our way of thinking the subcortical and/or unconscious processes that anticipate conscious emotional experiences.

In any case, it is important to realize that all comments raised in this paper do not address my personal opinion on the matter.

\section{LeDoux's Model of High-Order Conscious Emotion}

Claiming that emotion is a cognitive process or has a cognitive nature is hardly new (Lazarus 1981, 1984; Oatley and Johnson-Iard 1987; Gray 1990; Duncan and Barrett 2007). What distinguishes LeDoux and Brown's model of emotion is not just the claim that emotion is a cognitive process, but rather that emotion is always a conscious state of mind carried 
out only by frontal mechanisms, putting emotion into the same category of any other conscious state of mind. That is, LeDoux and Brown break with both the long tradition of attributing emotional processes to subcortical mechanisms and the tradition of directly linking emotion to unconscious processes in the brain, explicitly embracing a high-order view of emotion.

In the literature, it is common to link emotion to unconscious processes associated with the survival of the organism, so that emotion has been taken as a phenomenon directly linked to survival by many prominent authors (Darwin 1872; Panksepp 1982, 1998, 2000, 2005; Ekman 1972, 1984, 1992; Ekman et al. 1983; Lazarus 1991; Izard 1992; Damasio 1994, 1999, 2010; Kreibig 2010; Levenson 2014), which here I will call "traditional view of emotion." LeDoux himself used to see emotion as an unconscious process carried out before a comprehensive cognitive and conscious appraisal of the stimulus (LeDoux 1995, 1996, 2000). However, LeDoux has recently proposed another theoretical paradigm for emotion, dissociating this phenomenon from the activation of survival circuits, which are carried out mainly by subcortical mechanisms (LeDoux 2012, 2014, 2015; LeDoux and Pine 2016; LeDoux and Brown 2017). According to LeDoux (2015), there is no conceptual difference between emotion and feeling, being both conscious experiences of an emotional state. But on what exactly is based this conceptual shift?

LeDoux and Brown do in fact provide a large number of data demonstrating that the triggering of survival circuits, such as amygdala activation, does not necessarily trigger a conscious perception of fear (LeDoux 2014; LeDoux and Brown 2017), since there is an absence of the feeling of fear in the presentation of masked threat stimuli, even when they trigger survival reactions (Morris et al. 1999; Williams et al. 2006; Bornemann et al. 2012), which also happens with blindsight patients (Morris et al. 2001; Tamietto and de Gelder 2010). Furthermore, there is a permanence of the experience of fear even in the face of bilateral damage to the amygdala (Anderson and Phelps 2002; Feinstein et al. 2013). However, in my view, it is not sufficient (logically speaking) to claim that the emotion is not carried out by subcortical mechanisms (at least also by subcortical mechanisms).

This particular set of data does not guarantee that there is no unconscious emotional reaction. These data are, in fact, a hard blow against specific affective models that claim an independence between cognitive and affective processes, as advocated by Zajonc (1984), since this view separates affective emotional processes from cognitive processes and advocates that it is possible to have an emotional reaction without cognitive processes. Thus, by masking the stimulus, we withdraw any cognitive appraisal from the equation, and, according to this particular view, it should not interfere with the participant's affective reaction, which is not the case. However, nowadays, most of affective models of emotion take into consideration the importance of both cognitive and affective processes in the creation of emotional states (Pessoa 2010; Panksepp et al. 2016).

Therefore, although important, the point is not actually just about the distinction between conscious emotional experience and survival mechanisms. What really matters here is the theoretical background of the model. Thus, to understand the issue here, we must first understand the background of LeDoux and Brown's model of conscious and cognitive emotion, that is, we must analyze their theoretical model of consciousness to then analyze how this model implies on their model of emotion.

LeDoux $(2012,2015)$ had made some references to Baars' global workspace, according to which consciousness (including emotional consciousness) would be given through the broadcasting and rebroadcasting of information in the brain, and the information would just become conscious when it reaches the global workspace and is broadcasted throughout the brain (Baars 1988). LeDoux (2015) even theorized about a possible model to explain emotional processes, which the author called emotional soup. From this model, LeDoux hypothesized that emotional experience would take place through a set of numerous non-emotional neural and body processes (which he calls nonsoup ingredients), such as sensory processing, activation of survival circuit, brain arousal, body responses, mnemonic mechanisms, and executive functions, which together would give rise to an emotional experience through the working memory (forming then a soup). ${ }^{1}$ However, LeDoux did not follow through with this model of emotion, adopting instead Brown's HOROR theory of phenomenal consciousness (Brown 2015; LeDoux and Brown 2017). But, in one way or another, LeDoux maintains the cognitive background.

HOROR theory, like any other high-order theory of consciousness, requires a self. According to the theory, when we look at an object, for example, we cannot be aware of it only through its first-order representation, this representation must be placed into the working memory so that we can have a thought about the representation (high-order state), and, most importantly, this thought must be directed to ourselves. Only through this cognitive mechanism it is possible to have a conscious experience of the object (Rosenthal 2005; LeDoux 2015). The novelty proposed by Brown (2015) is that even a high-order representation can be re-represented giving rise to a thought about a thought (introspection). Thus, any emotional state must be directed to a self, without which it would not be possible to have any emotional experience; however, this model does not require self-consciousness per se (LeDoux and Brown 2017), that is, this model requires a self, but not a self that it conscious of itself.

Thus, according to this point of view, any first-order representation cannot give rise to any conscious experience by

\footnotetext{
${ }^{1}$ As the reader can see, LeDoux followed the same premise used by Baars (1988), that is, consciousness is given through a set of unconscious processes in the brain.
} 
itself, requiring a re-representation by high-order mechanisms to become conscious, which is completely in accordance with the methodology embraced by the authors to measure conscious activity, based on conscious reports (which demands introspection). Conscious reports are vastly correlated with (pre)frontal mechanisms (Frith et al. 1999; Dehaene and Naccache 2001; Dehaene, Changeux, Naccache, Sackur, and Sergent 2006; Del Cul et al. 2009; Lau 2008; Dehaene and Changeux 2011; Dehaene 2014), so it is not unexpected that LeDoux and Brown took these areas as the responsible for the creation of high-order representations, forming what they call general networks of cognition (GNC), which consists mainly of prefrontal mechanisms (anterior cingulate cortex, lateral orbitofrontal cortex, medial orbitofrontal cortex, dorsolateral prefrontal cortex, dorsomedial prefrontal cortex, ventrolateral prefrontal cortex, and ventromedial prefrontal cortex), along with the insula and the posterior parietal cortex (LeDoux 2015; LeDoux and Brown 2017).

According to the High-order Theory of Emotional Consciousness (HOTEC) proposed by LeDoux and Brown (2017), subcortical mechanisms, instead, are responsible just for providing (unconscious) first-order representations that may or may not participate in the creation of a particular emotional experience, such as the activation of survival mechanisms and body feedback, which, for example, may participate in the feeling of fear. That is, these first-order representations participate only indirectly in the creation of an emotional state of mind (LeDoux and Brown 2017). It is important to realize that LeDoux and Brown are not talking about implicit emotional reactions (Vandekerckhove and Panksepp 2011), according to them, instead, subcortical first-order representations are unconscious and participate only indirectly in the creation of an emotional state of mind, which is quite clear in the following statement:

As viewed here, defensive survival circuits indirectly contribute to the feeling of fear, but their activity does not constitute fear (LeDoux and Brown 2017, pp. E2017).

In our opinion, the subcortical circuits proposed by Panksepp and Damasio are better interpreted as contributing nonconscious first-order representations that indirectly influence the higherorder assembly of conscious feelings by the GNC (Idem, pp. E2019, italic mine).

Therefore, according to the high-order theory of emotional consciousness proposed by LeDoux and Brown (2017), the activation of subcortical and/or unconscious processes (which are also carried out by cortical areas, such as the visual cortex) is not sufficient to give rise to an emotional state of mind, the latter occurs only when the information is re-represented by the GNC. There is no unconscious emotion.
According to the authors, as well as to Barrett and colleagues (Barrett 2006a; Barrett et al. 2007), the direct stimulation of the amygdala does not give rise to the conscious experience of fear. The emotional experience depends on what the LeDoux and Brown call emotional schemas, which consist of our autobiographical memories on what a particular emotion represents. So, in a sense, we can say that LeDoux's model of conscious emotion is similar to the model of constructed emotion proposed by Barrett (2006b, 2017), but there are significant differences that must be pointed out:

1) Barrett (2006b, 2017) advocates that emotions have no specific neural circuitry, being, actually, only a conceptual category, such as "money" (Barrett 2017); however, as we have seen, LeDoux and Brown (2017) propose that emotional states are processed by the GNC, as well as any conscious process.

2) Barrett's model of constructed emotion is based on what is called "core affect," which is based on valence and arousal, where valence is mainly carried out by mechanisms of the orbitofrontal cortex, while arousal is mainly carried out by amygdala activation (Wilson-Mendenhall et al. 2013). LeDoux (2012), however, argues that valence and arousal are probably unconscious processes linked to survival circuits, which participate only indirectly in the construction of emotional states by the GNC (LeDoux and Brown 2017).

3) According to Barrett's model, the emotional categories are constricted by means of the physiological modulation of the core affect (which consists of valence and arousal) (Barrett 2006b). On the other hand, according to LeDoux's model, those processes participate only indirectly in the construction of emotional states by the GNC. That is, according to LeDoux, it is the GNC that have the functional priority.

In one way or another, I hope that it is clear that LeDoux and Brown's model of conscious emotion is based on a highorder theory of consciousness, where the unconscious subcortical and cortical first-order representations participate only indirectly in the creation of emotional states of mind by the GNC, so that the emotional state depends on the emotional schema of the individuals, and not only on the activation of subcortical and unconscious mechanisms.

\section{The Explanatory Power}

As we were able to see, LeDoux and Brown's model of conscious emotion is based on the HOROR theory of consciousness, placing emotional states into the same category of perceptual consciousness. Now, we need to analyze how this model answers some empirical and theoretical issues within 
the literature on emotion, that is, we need to analyze its explanatory power. Here, I chose to analyze two important topics: the debate on nonhuman emotional consciousness; and, since LeDoux's model is based on a view of conscious emotion carried out by prefrontal mechanisms, it is important to briefly review some recent controversies in relation to the role of prefrontal areas in conscious activity.

\section{Nonhuman Emotional Experience}

Unlike Panksepp (1998, 2000, 2005, 2010a, b, 2011), who was a prominent author who devoted much of his academic effort to the issue of nonhuman consciousness, LeDoux has not delve into this issue directly.

As we have seen, LeDoux and Brown propose a model of emotion based on prefrontal mechanisms along with the insula and the posterior parietal cortex (LeDoux and Brown 2017). So, how exactly can we consider that other animals have emotional consciousness (conscious experience of emotional states) if we do not consider a subcortical model of consciousness?

As we know, there are animals, such as gray parrots and corvids, which show intricate cognitive abilities, such as inferential reasoning and planning (Güntürkün and Bugnyar 2016), besides having a number of neurons comparable with (or even greater than) some primates (Olkowicz et al. 2016). However, they do not have cerebral cortex (Güntürkün and Bugnyar 2016).

Even LeDoux used to use the concept of "fear" to address the behavior of rodents during fear conditioning (Phelps and LeDoux 2005). It happens because we commonly infer emotional states through behavior, in both humans and nonhuman animals (Hall 1934; Panksepp 1998, 2005, 2010a, b, 2011; Fabbro et al. 2015). The justification for doing so is the evolutionary argument, that is, since we have emotional experience, it is very likely that we inherited it from other animals. This position fully agrees with traditional view of emotion, which links this phenomenon to survival circuits (LeDoux 2012, 2015). And since these survival circuits were inherited from evolution, it is possible that so was the emotional experience, especially given the fact that subcortical mechanisms are evolutionarily older than cortical structures. So, since they were inherited, we can, according to this view, infer emotional experience even in animals that do not have cerebral cortex through observation of behavior, like birds and insects (Anderson and Adolphs 2014; Gibson et al. 2015).

LeDoux (2015), on the other hand, believes that nonhuman animals may have creature consciousness, that is, they are alive and respond to their environments. However, there is little empirical evidence to corroborate that they have mental state consciousness, since the usual methodology to attest it is through conscious reports (LeDoux and Brown 2017). As we have seen, LeDoux and Brown's model of emotion is based on the self, so that a first-order state must be re-represented by a high-order state through a thought directed to the self, thus, an animal can only have emotional experience if it has neural mechanisms that sustain such a self.

It could be argued that some models within the traditional view of emotion (which links emotion to survival), as Damasio's model of emotional feelings, are also based on the self (Damasio 1999, 2010; Damasio and Carvalho 2013). However, Damasio's concept of core self consists mainly of subcortical representations, which is opposite of LeDoux and Brown's model of emotion based on high-order cortical representations.

Thus, since LeDoux advocates, along with most cognitive neuroscientists, a cortical and cognitive background of consciousness, we cannot claim, through this model, that animals without cortical mechanisms can have any kind of conscious experience, which, following LeDoux and Brown's model, includes emotional consciousness. But the authors really present us good explanations for this position. First of all, it is really difficult (or even impossible) to know how a nonhuman emotional experience is, that is, how nonhuman animals feel, since they cannot transmit it through language (LeDoux 2015; LeDoux and Brown 2017). Second, how can we overcome the anthropomorphism? Most people attribute wishes and intentions to their pets, even cognitive and behavioral processes that we know they do not possess, such as language comprehension (LeDoux, 2015). So, how could we provide a model that parsimoniously addresses the possibility of consciousness in nonhuman animals without being biased by an anthropomorphist view, especially when we consider animals far from us from an evolutionary perspective, such as fishes, insects, and birds?

Attempting to respond to this empirical problem, Paul and colleagues proposed an interesting model through which, according to the authors, it would be possible to assess the cognitive aspect of nonhuman emotional experience (Paul et al. 2005). However, this model is based on cognitive processes that can occur without mental state consciousness (conscious experience), as appraisal processes, attention, memory, and judgment. Appraisal processes can occur without consciousness, as demonstrated by the activation of survival circuits not followed by a respective emotional state of mind, as mentioned above (LeDoux and Brown 2017); attention can also occur without consciousness, it is consciousness that cannot occur without attention (Koch and Tsuchiya 2007); semantic memory can occur without mental state consciousness, that is, this type of memory occurs without addressing a self (LeDoux 2015); and there is still a heated discussion on the possibility of unconscious judgment/decision making (Libet et al. 1983) and decision making without attention ${ }^{2}$ (Dijksterhuis et al. 2006). Therefore, although these authors attempted to provide a cognitive view of emotional experience in other animals, the

\footnotetext{
${ }^{2}$ Remember that there is no consciousness without attention (Koch and Tsuchiya 2007).
} 
model fails to provide a compelling justification of how we would be able to parsimoniously approach emotional experience in nonhuman animals, since we can explain these cognitive processes without addressing mental state consciousness. As argued by LeDoux and Brown (2017) in "Box 3" of their paper, although consciousness depends on working memory, attention, and metacognition to occur, the occurrence of these cognitive processes is not sufficient to give rise to consciousness.

Moreover, as mentioned above, there are several studies showing that the activation of survival circuits and body reactions do not give rise to a conscious experience of what is happening (Morris et al. 1999; Morris et al. 2001; Anderson and Phelps 2002; Williams et al. 2006; Tamietto and de Gelder 2010; Bornemann et al. 2012; Feinstein et al. 2013). So, how could it be possible to have a subcortical activation without having any emotional experience if these mechanisms were really sufficient to carry out this state of mind? This drives difficult empirical problems for many models that follow a traditional view of emotion.

\section{Prefrontal Functioning}

Since LeDoux and Brown's model of emotion is based on a cortical background of consciousness, it is important to briefly review the relationship between prefrontal functioning and conscious activity.

As we have seen, this model of emotion is based on what the authors call general networks of cognition (GNC), which is mainly constituted by prefrontal cortices (LeDoux and Brown 2017). There is in fact a great deal of data suggesting that prefrontal functioning is one of (or even the most important of) the neural correlates of consciousness (NCCs) (Dehaene and Naccache 2001; Dehaene and Changeux 2011; Dehaene 2014; Lau 2008). However, the functional role of the prefrontal cortex in conscious activity has been questioned (Aru et al. 2012; Frässle et al. 2014; Safavi et al. 2014; Koch et al. 2016). For example, extensive lesions in the prefrontal cortex did not compromise conscious activity (Brickner 1952; Philippi et al. 2012; Koch et al. 2016), and it is still debated whether prefrontal functioning is actually more correlated with cognitive mechanisms necessary for conscious activity, such as executive functions (Aru et al. 2012), active report (Frässle et al. 2014; Tsuchiya et al. 2015), and introspection (Frässle et al. 2014), than with consciousness itself.

But, in any case, the correlation between cortical functioning and consciousness is still strong (Koch et al. 2016). Koch and colleagues, for example, have proposed just another perspective: the importance of the posterior cortices for conscious activity (Koch et al. 2016; Tononi et al. 2016), since they propose that sensory processing is a better way to attest conscious activity. But their view also has some problems. As well pointed out by Sandberg and colleagues, some sensory processes, such as gustatory process, are partially located in the frontal lobe, so that it would be better to reformulate what the Koch and colleagues call posterior cortical hot zone (Sandberg et al. 2016). Moreover, taking this discussion to our main focus here, it would still be necessary to investigate whether posterior mechanisms are also responsible for the processing of emotional states, since they also are conscious states of mind (according to LeDoux, of course) and several prefrontal mechanisms have been correlated with the experience of emotional states, such as the anterior cingulate cortex (Bush et al. 2000; Etkin et al. 2006; Etkin et al. 2011) and the orbitoprefrontal cortex (Bechara et al. 2000; Rempel-Clower 2007).

In one way or another, since LeDoux and Brown (2017) consider that emotion is in the same category of perceptual consciousness, it is necessary to further investigate whether these same prefrontal mechanisms are actually correlated with the integration of emotional perceptual information, or whether they are only correlated with report and introspection of emotional states rather than giving rise to (emotional) consciousness itself.

\section{The Interpretation of the Data}

Since LeDoux and Brown present a new model of emotion, proposing that emotion is always a conscious state of mind carried out by the GNC, whose empirical verification is based on conscious reports, it is quite expected that this view may change our way of designing experiments and interpreting the data.

For didactic purposes, here I am going to analyze how this model impacts on three examples of classical issues in the literature on emotion: freezing, emotion regulation, and pleasure mechanisms (in contrast to the example of fear discussed by LeDoux and colleagues), assessing how this model of conscious emotion may influence the interpretation of the data.

\section{Freezing Behavior}

Since Blanchard and Blanchard's classical publication, freezing is now a well-known fear response, which, at the time, was conceptualized by the authors as crouching (Blanchard and Blanchard 1969). And, as expected, nowadays, we know much better how this response to threats is processed in the brain (LeDoux et al. 1988; LeDoux 1996, 2015).

Here, I will follow the same example addressed by LeDoux (1994, 2015): the low road of stimulus processing. When we look at an object that seems threatening, due to survival purposes, our reaction to this stimulus occurs long before a comprehensive cognitive and conscious appraisal of it. When 
survival is at stake, every hundredth of a second counts. It happens because our visual thalamus carries out a preappraisal of the stimulus based on innate information, such as the shape of a snake (which is an innate threat stimulus), and if the stimulus coincides with this information, the thalamus sends inputs to the amygdala (low road), initiating the activation of the survival mechanisms, such as freezing (behavioral survival response) (LeDoux 1994, 2015).

Many authors of the traditional view of emotion, such as Damasio (1994, 1999, 2010) and Panksepp (1998, 2005, 2010b), classify the activation of the amygdala in such circumstances as fear. Panksepp (2005), for example, call the low road mentioned above "trans-hypothalamic FEAR system" (Panksepp 2005, pp.50). However, if we adopt LeDoux and Brown's model of emotion, the activation of the amygdala represents only the activation of survival circuits, which may or may not participate in the construction of an emotional state of mind (emotion), since, according to the authors, emotion is always a conscious experience (the model, as we have seen, does not admit "unconscious" or "implicit" emotional states). According to this model, when we look at the same neuroimaging data of the example above, what attests the experience of emotion is the activation of the general networks of cognition discussed above (LeDoux and Brown 2017), not the activation of the amygdala. Therefore, freezing is not a reaction of fear (it is not an emotional behavior), but rather a survival reaction (it is a survival behavior). According to the model, what attests the emotional state is only the conscious experience of it, which is confirmed by the participant through communication mechanisms.

\section{Emotion Regulation}

Emotion regulation is still a hot topic in the literature on emotion. Sometimes, this topic is approached not even assessing the (possible) neural mechanisms responsible for it, taking into consideration only the (possible) cognitive mechanisms responsible for such a process (Gross and Barrett 2011; Gross 2013; Naragon-Gainey et al. 2017), but what matters to us here are the neural underpinnings of emotion regulation.

The interaction between the amygdala and the prefrontal cortices is often addressed as the possible neural mechanism for emotion regulation (Banks et al. 2007; Silvers et al. 2016; Hogeveen et al. 2016; Morawetz et al. 2017). For example, Banks and colleagues, together with Aggleton (1993), argue that the amygdala is also responsible for the experience of negative emotions (Banks et al. 2007). According to these authors, it is the interaction between the amygdala and prefrontal regions (such as the anterior cingulate cortex, the right orbitofrontal cortex, the left orbitofrontal cortex, and the (ventral) medial prefrontal cortex) that is responsible for emotion regulation (Banks et al. 2007). Similar results were found by Silvers and colleagues, where the authors argue that adult participants showed reduced negative responses and reduced amygdala activation in reappraisal trials of negative images (Silvers et al. 2016). These authors interpreted the empirical data based on the view that amygdala is an area responsible for emotional states, that is, that the activation of the amygdala is highly correlated with emotional reactions. However, the empirical landscape changes significantly when we interpret the data based on LeDoux and Brown's model of emotion.

According to this model, the amygdala is not part of the network for emotional states of mind. This area is instead responsible for the activation of survival circuits, thus, the most obvious implication is that the authors should not consider the amygdala as an area responsible for emotion regulation. In addition, since the general networks of cognition (GNC) are responsible for carrying out emotional states, the function of the prefrontal cortices addressed by the aforementioned authors would rather regulate the activation of the survival mechanisms, such as amygdala activation. For example, as discussed earlier, when we look at an object that may be a snake (due to shape, pattern of movement, etc.), the thalamus sends inputs to the amygdala initiating the survival responses. But when a comprehensive cognitive appraisal of the stimulus is carried out by cortical areas, and we then realize that the object is actually a stick (LeDoux 2015), for example, the survival reactions are disrupted, so that the body leaves the state of freezing. Therefore, the function of the prefrontal cortex, according to this model, is not interrupt an ongoing emotional reaction, but rather survival reactions that are not directly linked to one's emotional state (which is always conscious). Thus, since emotions are cognitive processes (LeDoux 2015; LeDoux and Brown 2017), when Silvers and colleagues discuss the data, the differences between youngsters and adults can be given by cognitive maturity, which is probably underlined by prefrontal mechanisms (Anderson et al. 2001; Johnson et al. 2009). In this way, adult brains, due to cortical maturation, probably have mechanisms to disrupt survival reactions faster than younger brains, thereby reducing subsequent emotional reactions. Since emotional states are carried out by the general network of cognition, only the prefrontal mechanisms, together with the insula and the posterior parietal cortex, are responsible for carrying out emotional states of mind. Thus, the mediation of the ventromedial prefrontal cortex in the interaction between the ventrolateral prefrontal cortex and the amygdala (Silvers et al. 2016) is only to control the activity of survival mechanisms, which becomes stronger from cortical maturation.

\section{Pleasure Mechanisms}

We often find in the literature on neural mechanisms of pleasure that subcortical areas, such as the nucleus accumbens, the ventral pallidum, the striatum, and the amygdala, are some of those responsible for the experience of pleasure, along with 
prefrontal regions, such as the orbitofrontal cortex, anterior cingulate cortex, the dorsolateral prefrontal cortex, and the insula (Berridge and Kringelbach 2008, 2015). Again, if we consider that subcortical and/or unconscious mechanisms directly participate in the construction of emotional states, this view would have no problems. However, again, if we adopt LeDoux and Brown's model of emotion, the interpretive landscape changes.

LeDoux has rightly argued that reinforcement processing, arousal, and survival mechanisms, although somehow linked to emotional states, are not emotional processes (LeDoux 2012, 2015). Reinforcement learning (reward-seeking), for example, is probably an evolutionary mechanism of adaptation and survival (Schultz 2015; Loonen and Ivanova 2015). This mechanism was found in numerous species, with or without cerebral cortex, such as birds and fishes (Doya and Sejnowski 1995; Graybiel 2005; Agrillo et al. 2012). Following LeDoux and Brown's model of conscious emotion, the needlessness of cortical mechanisms for reward-seeking only corroborates the separation of emotional states of mind (processed by cortical mechanisms of consciousness) and reward processing, especially due to the fact that reinforcement learning can occur unconsciously (Seitz et al. 2009; Xue et al. 2015). Thus, a possible explanation for the apparent participation of subcortical mechanisms in the experience of pleasure is that these areas actually participate in reward processing, as has already been shown by previous studies (Baxter and Murray 2002; Balleine et al. 2007; Smith et al. 2009; Gale et al. 2014; Wassum and Izquierdo 2015), which may provide (unconscious) first-order representations for the creation of an emotional state of mind by the GNC. Therefore, according to LeDoux and Brown's model, those authors who interpret the participation of subcortical regions in the experience of pleasure may be attributing to them an emotional function rather than just the function of processing reward values (first-order representations), which does not depend on conscious activity to occur. The experience of pleasure only occur when the GNC process (re-represent) this particular subcortical information.

As we can see, the theoretical model proposed by LeDoux and colleagues impacts directly on how we interpret the data, and, in the future, it may also impact on how we design experiment to investigate the neural underpinnings of emotional states. And it is the importance of such a thing that I tried to demonstrate here.

\section{Conclusion}

Emotion research depends directly on what we call emotion. Any difference in the conceptual model of this phenomenon will directly impact on how we design the experiments and how we assess and discuss the data. So, since LeDoux and colleagues have proposed that emotion is a high-order state carried out by frontal mechanisms, it is expected that this model, if corroborated by future research, may change what we regard as emotion and how to investigate it. I really hope that the discussion carried out in this review can provide theoretical tools to facilitate the understanding of this current empirical and theoretical issue.

Funding Information This paper was supported by São Paulo Research Foundation (FAPESP).

\section{Compliance with Ethical Standards}

Conflict of Interest The author declares that he has no conflict of interest.

\section{References}

Aggleton, J. P. (1993). The contribution of the amygdala to normal and abnormal emotional states. Trends in Neurosciences, 16, 328-333. https://doi.org/10.1016/0166-2236(93)90110-8.

Agrillo, C., Miletto Petrazzini, M. E., Piffer, L., Dadda, M., \& Bisazza, A. (2012). A new training procedure for studying discrimination learning in fish. Behavioural Brain Research, 230, 343-348. https://doi. org/10.1016/j.bbr.2012.02.025.

Anderson, D. J., \& Adolphs, R. (2014). A framework for studying emotions across phylogeny. Cell, 157, 187-200. https://doi.org/10.1016/ j.cell.2014.03.003.

Anderson, A. K., \& Phelps, E. A. (2002). Is the human amygdala critical for the subjective experience of emotion? Evidence of intact dispositional affect in patients with amygdala lesions. Journal of Cognitive Neuroscience, 14, 709-720. https://doi.org/10.1162/ 08989290260138618.

Anderson, V. A., Anderson, P., Northam, E., Jacobs, R., \& Catroppa, C. (2001). Development of executive functions through late childhood and adolescence in an Australian sample. Developmental Neuropsychology, 20, 385-406. https://doi.org/10.1207/ S15326942DN20015.

Aru, J., Bachmann, T., Singer, W., \& Melloni, L. (2012). Distilling the neural correlates of consciousness. Neuroscience and Biobehavioral Reviews, 36, 737-746. https://doi.org/10.1016/j.neubiorev.2011.12. 003.

Baars, B. J. (1988). A cognitive theory of consciousness. New York: Cambridge University Press.

Balleine, B. W., Delgado, M. R., \& Hikosaka, O. (2007). The role of the dorsal striatum in reward and decision-making. The Journal of Neuroscience, 27, 8161-8165. https://doi.org/10.1523/ JNEUROSCI.1554-07.2007.

Banks, S. J., Eddy, K. T., Angstadt, M., Nathan, P. J., \& Phan, K. L. (2007). Amygdala - frontal connectivity during emotion regulation. Social Cognitive and Affective Neuroscience, 2, 303-312. https:// doi.org/10.1093/scan/nsm029.

Barrett, L. F. (2006a). Are emotions natural kinds? Perspectives on Psychological Science, 1, 28-58. https://doi.org/10.1111/j.17456916.2006.00003.x.

Barrett, L. F. (2006b). Solving the emotion paradox: categorization and the experience of emotion. Personality and Social Psychology Review, 10, 20-46. https://doi.org/10.1207/s15327957pspr1001_2.

Barrett, L. F. (2017). The theory of constructed emotion: an active inference account of interoception and categorization. Social Cognitive 
and Affective Neuroscience, 12, 1-23. https://doi.org/10.1093/scan/ nsw154.

Barrett, L. F., Lindquist, K. A., Bliss-Moreau, E., Duncan, S., Gendron, M., Mize, J., \& Brennan, L. (2007). Of mice and men: natural kinds of emotions in the mammalian brain? A response to Panksepp and izard. Perspectives on Psychological Science, 2, 297-312. https:// doi.org/10.1111/j.1745-6916.2007.00046.x.

Baxter, M. G., \& Murray, E. A. (2002). The amygdala and reward. Nature Reviews. Neuroscience, 3, 563-573. https://doi.org/10.1038/nrn875.

Bechara, A., Damasio, H., \& Damasio, A. R. (2000). Emotion, decision making and the orbitofrontal cortex. Cerebral Cortex, 10, 295-307. https://doi.org/10.1093/cercor/10.3.295.

Berridge, K. C., \& Kringelbach, M. L. (2008). Affective neuroscience of pleasure: reward in humans and animals. Psychopharmacology, 199, 457-480. https://doi.org/10.1007/s00213-008-1099-6.

Berridge, K. C., \& Kringelbach, M. L. (2015). Pleasure systems in the brain. Neuron, 86, 646-664. https://doi.org/10.1016/j.neuron.2015. 02.018 .

Blanchard, R. J., \& Blanchard, D. C. (1969). Crouching as an index of fear. Journal of Comparative and Physiological Psychology, 67, 370-375. https://doi.org/10.1037/h0026779.

Bornemann, B., Winkielman, P., \& van der Meer, E. (2012). Can you feel what you do not see? Using internal feedback to detect briefly presented emotional stimuli. International Journal of Psychophysiology, 85, 116-124. https://doi.org/10.1016/j.ijpsycho. 2011.04.007.

Brickner, R. M. (1952). Brain of patient A. After bilateral frontal lobectomy; status of frontal-lobe problem. A.M.A. Archives of Neurology and Psychiatry, 68, 293-313. https://doi.org/10.1001/archneurpsyc. 1952.02320210003001 .

Brown, R. (2015). The HOROR theory of phenomenal consciousness. Philosophical Studies, 172, 1783-1794. https://doi.org/10.1007/ s11098-014-0388-7.

Bush, G., Luu, P., \& Posner, M. (2000). Cognitive and emotional influences in anterior cingulate cortex. Trends in Cognitive Sciences, 4, 215-222. https://doi.org/10.1016/S1364-6613(00)01483-2.

Damasio, A. R. (1994). Descartes' error: emotion, reason and the human brain. New York: Putnam.

Damasio, A. R. (1999). The feeling of what happens: body and emotion in the making of consciousness. San Diego: Harcourt.

Damasio, A. R. (2010). Self comes to mind: constructing the conscious brain. New York: Pantheon.

Damasio, A. R., \& Carvalho, G. B. (2013). The nature of feelings: evolutionary and neurobiological origins. Nature Reviews Neuroscience, 14, 143-152. https://doi.org/10.1038/nrn3403.

Darwin, C. (1872). The expression of the emotions in man and animals. London: Fontana Press.

Dehaene, S. (2014). Consciousness and the brain: deciphering how the brain codes our thoughts. New York: Viking Adult.

Dehaene, S., \& Changeux, J. P. (2011). Experimental and theoretical approaches to conscious processing. Neuron, 70, 200-227. https:// doi.org/10.1016/j.neuron.2011.03.018.

Dehaene, S., \& Naccache, L. (2001). Towards a cognitive neuroscience of consciousness: basic evidence and a workspace framework. Cognition, 79, 1-37. https://doi.org/10.1016/S0010-0277(00) 00123-2.

Dehaene, S., Changeux, J.-P., Naccache, L., Sackur, J., Sergent, C. (2006). Conscious, preconscious, and subliminal processing: a testable taxonomy. Trends in Cognitive Sciences, 10(5), 204-211.

Del Cul, A., Dehaene, S., Reyes, P., Bravo, E., \& Slachevsky, A. (2009). Causal role of prefrontal cortex in the threshold for access to consciousness. Brain, 132, 2531-2540. https://doi.org/10.1093/brain/ awp111.

Dijksterhuis, A., Bos, M. W., Nordgren, L. F., \& van Baaren, R. B. (2006). On making the right choice: the deliberation-without- attention effect. Science, 311, 1005-1007. https://doi.org/10.1126/ science. 1121629.

Doya, K., \& Sejnowski, T. J. (1995). A novel reinforcement model of birdsong vocalization learning. In G. Tesauro, D. S. Touretzky, \& T. $\mathrm{K}$. Leen (Eds.), Advances in neural information processing systems (Vol. 7, pp. 101-108). Cambridge: The MIT Press.

Duncan, S., \& Barrett, L. F. (2007). Affect is a form of cognition: a neurobiological analysis. Cognition and Emotion, 21, 1184-1211. https://doi.org/10.1080/02699930701437931.

Ekman, P. (1972). Universals and cultural differences in facial expressions of emotions. In J. Cole (Ed.), Nebraska symposium on motivation, 1971 (pp. 207-283). Lincoln: University of Nebraska Press.

Ekman, P. (1984). Expression and nature of emotion. In K. Scherer \& P. Ekman (Eds.), Approaches to emotion (pp. 319-343). Hillsdale: Earlbaum.

Ekman, P. (1992). An argument for basic emotions. Cognition and Emotion, 6, 169-200.

Ekman, E., Levenson, R. W., \& Friesen, W. V. (1983). Autonomic nervous system activity distinguishes among emotions. Science, 221, 1208-1210. https://doi.org/10.1126/science.6612338.

Etkin, A., Egner, T., Peraza, D. M., Kandel, E. R., \& Hirsch, J. (2006). Resolving emotional conflict: a role for the rostral anterior cingulate cortex in modulating activity in the amygdala. Neuron, 51, 871-882. https://doi.org/10.1016/j.neuron.2006.07.029.

Etkin, A., Egner, T., \& Kalisch, R. (2011). Emotional processing in anterior cingulate and medial prefrontal cortex. Trends in Cognitive Sciences, 15, 85-93. https://doi.org/10.1016/j.tics.2010.11.004.

Fabbro, F., Aglioti, S. M., Bergamasco, M., Clarici, A., \& Panksepp, J. (2015). Evolutionary aspects of self- and world consciousness in vertebrates. Frontiers in Human Neuroscience, 9, 157. https://doi. org/10.3389/fnhum.2015.00157.

Feinstein, J. S., Buzza, C., Hurlemann, R., Follmer, R. L., Dahdaleh, N. S., Coryell, W. H., et al. (2013). Fear and panic in humans with bilateral amygdala damage. Nature Neuroscience, 16, 270-272. https://doi.org/10.1038/nn.3323.

Frässle, S., Sommer, J., Jansen, A., Naber, M., \& Einhäuser, W. (2014). Binocular rivalry: frontal activity relates to introspection and action but not to perception. The Journal of Neuroscience, 34, 1738-1747. https://doi.org/10.1523/JNEUROSCI.4403-13.2014.

Frith, C., Perry, R., \& Lumer, E. (1999). The neural correlates of conscious experience: an experimental framework. Trends in Cognitive Sciences, 3, 105-114. https://doi.org/10.1016/S1364-6613(99) 01281-4.

Gale, J. T., Shields, D. C., Ishizawa, Y., \& Eskandar, E. N. (2014). Reward and reinforcement activity in the nucleus accumbens during learning. Frontiers in Behavioral Neuroscience, 8, 114. https://doi. org/10.3389/fnbeh.2014.00114.

Gibson, W. T., Gonzalez, C. R., Fernandez, C., Ramasamy, L., Tabachnik, T., Du, R. R., et al. (2015). Behavioral responses to a repetitive visual threat stimulus express a persistent state of defensive arousal in Drosophila. Current Biology, 25, 1401-1415. https:// doi.org/10.1016/j.cub.2015.03.058.

Gray, J. A. (1990). Brain systems that mediate both emotion and cognition. Cognition and Emotion, 4, 269-288. https://doi.org/10.1080/ 02699939008410799.

Graybiel, A. M. (2005). The basal ganglia: learning new tricks and loving it. Current Opinion in Neurobiology, 15, 638-644. https://doi.org/ 10.1016/j.conb.2005.10.006.

Gross, J. J. (2013). Emotion regulation: taking stock and moving forward. Emotion, 13, 359-365. https://doi.org/10.1037/a0032135.

Gross, J. J., \& Barrett, L. F. (2011). Emotion generation and emotion regulation: one or two depends on your point of view. Emotion Review, 3, 8-16. https://doi.org/10.1177/1754073910380974.

Güntürkün, O., \& Bugnyar, T. (2016). Cognition without cortex. Trends in Cognitive Sciences, 20, 291-303. https://doi.org/10.1016/j.tics. 2016.02.001. 
Hall, C. S. (1934). Emotional behavior in the rat. I. Defecation and urination as measures of individual differences in emotionality. Journal of Comparative Psychology, 18, 385-403. https://doi.org/10.1037/ h0071444.

Hogeveen, J., Salvi, C., \& Grafman, J. (2016). 'Emotional intelligence': lessons from lesions. Trends in Cognitive Sciences, 39, 694-705. https://doi.org/10.1016/j.tins.2016.08.007.

Izard, C. E. (1992). Basic emotions, relations among emotions, and emotion-cognition relations. Psychology Review, 99, 561-565. https://doi.org/10.1037/0033-295X.99.3.561.

Johnson, S. B., Blum, R. W., \& Giedd, J. N. (2009). Adolescent maturity and the brain: the promise and pitfalls of neuroscience research in adolescent health policy. The Journal of Adolescent Health, 45, 216-221. https://doi.org/10.1016/j.jadohealth.2009.05.016.

Koch, C., \& Tsuchiya, N. (2007). Attention and consciousness: two distinct brain processes. Trends in Cognitive Sciences, 11, 16-22. https://doi.org/10.1016/j.tics.2006.10.012.

Koch, C., Massimini, M., Boly, M., \& Tononi, G. (2016). Neural correlates of consciousness: progress and problems. Nature Reviews. Neuroscience, 17, 307-321. https://doi.org/10.1038/nrn.2016.22.

Kreibig, S. D. (2010). Autonomic nervous system activity in emotion: a review. Biological Psychology, 84, 394-421. https://doi.org/10. 1016/j.biopsycho.2010.03.010.

Lau, H. C. (2008). A higher order Bayesian decision theory of consciousness. Progress in Brain Research, 168, 35-48. https://doi.org/10. 1016/S0079-6123(07)68004-2.

Lazarus, R. S. (1981). A cognitivist's reply to Zajonc on emotion and cognition. The American Psychologist, 36, 222-223. https://doi.org/ 10.1037/0003-066X.36.2.222.

Lazarus, R. S. (1984). On the primacy of cognition. The American Psychologist, 39, 124-129. https://doi.org/10.1037/0003-066X.39. 2.124 .

Lazarus, R. S. (1991). Cognition and motivation in emotion. The American Psychologist, 46, 352-367. https://doi.org/10.1037/ 0003-066X.46.4.352.

LeDoux, J. E. (1994). Emotion, memory and the brain. Scientific American, 270, 50-57.

LeDoux, J. E. (1995). Emotion: clues from the brain. Annual Review of Psychology, 46, 209-235. https://doi.org/10.1146/annurev.ps.46. 020195.001233 .

LeDoux, J. E. (1996). The emotional brain. New York: Simon and Schuster.

LeDoux, J. E. (2000). Emotion circuits in the brain. Annual Review of Neuroscience, 23, 155-184. https://doi.org/10.1146/annurev.neuro. 23.1.155

LeDoux, J. E. (2012). Rethinking the emotional brain. Neuron, 73, 653 676. https://doi.org/10.1016/j.neuron.2012.02.004.

LeDoux, J. E. (2014). Coming to terms with fear. Proceedings of the National Academy of Sciences of the United States of America, 111, 2871-2878. https://doi.org/10.1073/pnas.1400335111.

LeDoux, J. E. (2015). Anxious: unising the brain to understand and treat fear and anxiety. New York: Viking.

LeDoux, J. E., \& Brown, R. (2017). A higher-order theory of emotional consciousness. Proceedings of the National Academy of Sciences of the United States of America, 114, E2016-E2025. https://doi.org/10. 1073/pnas.1619316114.

LeDoux, J. E., \& Pine, D. S. (2016). Using neuroscience to help understand fear and anxiety: a two-system framework. The American Journal of Psychiatry, 173, 1083-1093. https://doi.org/10.1176/ appi.ajp.2016.16030353.

LeDoux, J. E., Iwata, J., Cicchetti, P., \& Reis, D. J. (1988). Different projections of the central amygdaloid nucleus mediate autonomic and behavioral correlates of conditioned fear. The Journal of Neuroscience, 8, 2517-2529.
Levenson, R. W. (2014). The autonomic nervous system and emotion. Emotion Review, 6, 100-112. https://doi.org/10.1177/ 1754073913512003

Libet, B., Gleason, C. A., Wright, E. W., \& Pearl, D. K. (1983). Time of conscious intention to act in relation to onset of cerebral activity (readiness-potential). The unconscious initiation of a freely voluntary act. Brain, 106, 623-642.

Loonen, A. J. M., \& Ivanova, S. A. (2015). Circuits regulating pleasure and happiness: the evolution of reward-seeking and misery-fleeing behavioral mechanisms in vertebrates. Frontiers in Neuroscience, 9 , 394. https://doi.org/10.3389/fnins.2015.00394.

Morawetz, C., Bode, S., Baudewig, J., \& Heekeren, H. R. (2017). Effective amygdala-prefrontal connectivity predicts individual differences in successful emotion regulation. Social Cognitive and Affective Neuroscience, 12, 569-585. https://doi.org/10.1093/scan/ nsw169.

Morris, J. S., Ohman, A., \& Dolan, R. J. (1999). A subcortical pathway to the right amygdala mediating "unseen" fear. Proceedings of the National Academy of Sciences of the United States of America, 96, 1680-1685. https://doi.org/10.1073/pnas.96.4.1680.

Morris, J. S., DeGelder, B., Weiskrantz, L., \& Dolan, R. J. (2001). Differential extrageniculostriate and amygdala responses to presentation of emotional faces in a cortically blind field. Brain, 124, 1241-1252. https://doi.org/10.1093/brain/124.6.1241.

Naragon-Gainey, K., McMahon, T. P., \& Chacko, T. P. (2017). The structure of common emotion regulation strategies: a meta-analytic examination. Psychological Bulletin, 143, 384-427. https://doi.org/10. 1037/bul0000093.

Oatley, K., \& Johnson-Iard, P. P. (1987). Towards a cognitive theory of emotions. Cognition and Emotion, 1, 29-50. https://doi.org/10. 1080/02699938708408362.

Olkowicz, S., Kocourek, M., Lučan, R. K., Porteš, M., Fitch, W. T., Herculano-Houzel, S., \& Němec, P. (2016). Birds have primatelike numbers of neurons in the forebrain. Proceedings of the National Academy of Sciences of the United States of America, 113, 7255-7260. https://doi.org/10.1073/pnas.1517131113.

Panksepp, J. (1982). Toward a general psychobiological theory of emotions. The Behavioral and Brain Sciences, 5, 407-467. https://doi. org/10.1017/S0140525X0001275.

Panksepp, J. (1998). Affective neuroscience: the foundations of human and animal emotions. New York: Oxford University Press.

Panksepp, J. (2000). Emotions as natural kinds within the mammalian brain. In M. Lewis \& J. M. Haviland-Jones (Eds.), Handbook of emotions (2th ed., pp. 137-156). New York: The Guilford Press.

Panksepp, J. (2005). Affective consciousness: core emotional feelings in animals and humans. Consciousness and Cognition, 14, 30-80. https://doi.org/10.1016/j.concog.2004.10.004.

Panksepp, J. (2010a). Affective consciousness in animals: perspectives on dimensional and primary process emotion approaches. Proceedings of the Biological Sciences, 277, 2905-2907. https:// doi.org/10.1098/rspb.2010.1017.

Panksepp, J. (2010b). Affective neuroscience of the emotional BrainMind: evolutionary perspectives and implications for understanding depression. Dialogues in Clinical Neuroscience, 12, 533545.

Panksepp, J. (2011). Cross-species affective neuroscience decoding of the primal affective experiences of humans and related animals. PLoS One, 6, e21236. https://doi.org/10.1371/journal.pone.0021236.

Panksepp, J., Lane, R. D., Solms, M., \& Smith, R. (2016). Reconciling cognitive and affective neuroscience perspectives on the brain basis of emotional experience. Neuroscience and Biobehavioral Reviews, 76, 187-215. https://doi.org/10.1016/j.neubiorev.2016.09.010.

Paul, E.S., Harding, E.J., \& Mendl, M. (2005). Measuring emotional processes in animals: the utility of a cognitive approach. Neuroscience and Biobehavioral Reviews, 29, 469-491. doi: https://doi.org/10.1016/j.neubiorev.2005.01.002. 
Pessoa, L. (2010). Emotion and cognition and the amygdala: from "what is it?" to "what's to be done?". Neuropsychologia, 48, 3416-3429. https://doi.org/10.1016/j.neuropsychologia.2010.06.038.

Phelps, E. A., \& LeDoux, J. E. (2005). Contributions of the amygdala to emotion processing: from animal models to human behavior. Neuron, 48, 175-187. https://doi.org/10.1016/j.neuron.2005.09. 025.

Philippi, C. L., Feinstein, J. S., Khalsa, S. S., Damasio, A., Tranel, D., Landini, G., Williford, K., Rudrauf, D., Hoshi, Y. (2012). Preserved Self-Awareness following Extensive Bilateral Brain Damage to the Insula, Anterior Cingulate, and Medial Prefrontal Cortices. PLoS ONE, 7 (8), e38413. https://doi.org/10.1371/journal.pone.0038413

Rempel-Clower, N. L. (2007). Role of orbitofrontal cortex connections in emotion. Annals of the New York Academy of Sciences, 1121, 72-86. https://doi.org/10.1196/annals.1401.026.

Rosenthal, D. M. (2005). Consciousness and mind. Oxford: Oxford University Press.

Safavi, S., Kapoor, V., Logothetis, N., \& Panagiotaropoulos, T. I. (2014). Is the frontal lobe involved in conscious perception? Frontiers in Psychology, 5, 1063. https://doi.org/10.3389/fpsyg.2014.01063.

Sandberg, K., Frässle, S., \& Pitts, M. (2016). Future directions for identifying the neural correlates of consciousness. Nature Reviews. Neuroscience, 17, 666. https://doi.org/10.1038/nrn.2016.104.

Schultz, W. (2015). Neuronal reward and decision signals: from theories to data. Physiological Reviews, 95, 853-951. https://doi.org/10. 1152/physrev.00023.2014.

Seitz, A. R., Kim, D., \& Watanabe, T. (2009). Rewards evoke learning of unconsciously processed visual stimuli in adult humans. Neuron, 61, 700-707. https://doi.org/10.1016/j.neuron.2009.01.016.

Silvers, J. A., Insel, C., Powers, A., Franz, P., Helion, C., Martin, R. E., et al. (2016). vlPFC-vmPFC-amygdala interactions underlie agerelated differences in cognitive regulation of emotion. Cerebral Cortex, 27, 3502-3514. https://doi.org/10.1093/cercor/bhw073.

Smith, K. S., Tindell, A. J., Aldridge, J. W., \& Berridge, K. C. (2009). Ventral pallidum roles in reward and motivation. Behavioural Brain Research, 196, 155-167. https://doi.org/10.1016/j.bbr.2008.09.038.
Tamietto, M., \& de Gelder, B. (2010). Neural bases of the non-conscious perception of emotional signals. Nature Reviews. Neuroscience, 11, 697-709. https://doi.org/10.1038/nrn2889.

Tononi, G., Boly, M., Massimini, M., \& Koch, C. (2016). Integrated information theory: from consciousness to its physical substrate. Nature Reviews. Neuroscience, 17, 450-461. https://doi.org/10. 1038/nrn.2016.44.

Tsuchiya, N., Wilke, M., Frässle, S., \& Lamme, V. A. F. (2015). No-report paradigms: extracting the true neural correlates of consciousness. Trends in Cognitive Sciences, 19, 757-770. https://doi.org/10. 1016/j.tics.2015.10.002.

Vandekerckhove, M., \& Panksepp, J. (2011). A neurocognitive theory of higher mental emergence: from anoetic affective experiences to noetic knowledge and autonoetic awareness. Neuroscience and Biobehavioral Reviews, 35, 2017-2025. https://doi.org/10.1016/j. neubiorev.2011.04.001.

Wassum, K. M., \& Izquierdo, A. (2015). The basolateral amygdala in reward learning and addiction. Neuroscience and Biobehavioral Reviews, 57, 271-283. https://doi.org/10.1016/j.neubiorev.2015.08. 017.

Williams, L. M., Das, P., Liddell, B. J., Kemp, A. H., Rennie, C. J., \& Gordon, E. (2006). Mode of functional connectivity in amygdala pathways dissociates level of awareness for signals of fear. The Journal of Neuroscience, 26, 9264-9271. https://doi.org/10.1523/ JNEUROSCI.1016-06.2006.

Wilson-Mendenhall, C. D., Barrett, L. F., \& Barsalou, L. W. (2013). Neural evidence that human emotions share core affective properties. Psychological Science, 24, 947-956. https://doi.org/10.1177/ 0956797612464242

Xue, X., Zhou, X., \& Li, S. (2015). Unconscious reward facilitates motion perceptual learning. Visual Cognition, 23, 161-178. https://doi. org/10.1080/13506285.2014.981625.

Zajonc, R. B. (1984). On the primacy of affect. American Psychologist, 39, 117-123. https://doi.org/10.1037/0003-066X.39.2.117. 